\title{
Optimal management of chronic osteomyelitis: current perspectives
}

This article was published in the following Dove Press journal:

Orthopedic Research and Reviews

3I August 2015

Number of times this article has been viewed

\section{Ketan C Pande}

Raja Isteri Pengiran Anak Saleha Hospital, Bandar Seri Begawan, Brunei

\begin{abstract}
Chronic osteomyelitis is a challenging condition to treat. It is seen mostly after open fractures or in implant-related infections following treatment of fractures and prosthetic joint replacements. Recurrence of infection is well known, and successful treatment requires a multidisciplinary team approach with surgical debridement and appropriate antimicrobial therapy as the cornerstone of treatment. Staging of the disease and identification of the causative microorganism is essential before initiation of treatment. Important surgical steps include radical debridement of necrotic and devitalized tissue, removal of implants, management of resultant dead space, soft-tissue coverage, and skeletal stabilization or management of skeletal defects. The route of administration and duration of antimicrobial therapy continues to be debated. The role of biofilm is now clearly established in the chronicity of bone infection, and newer modalities are being developed to address various issues related to biofilm formation. The present review addresses various aspects of chronic osteomyelitis of long bones seen in adults, with a review of recent developments.
\end{abstract}

Keywords: osteomyelitis, infection, biofilm, bone, therapy, treatment

\section{Introduction}

Chronic osteomyelitis is defined as long-standing infection of the bone characterized by persistence of microorganisms, presence of sequestrum, low-grade inflammation, and fistulae. ${ }^{1}$ It continues to be a challenge for orthopedic surgeons, as it is common after severe open fractures with gross contamination and compromised soft tissues, as well as following internal fixation of fractures and prosthetic joint-replacement surgery.

Its impact on function and mobility has been widely noted, particularly in the young productive patient population. The prolonged treatment involved affects ambulatory status, functional mobility, and independence. Staged surgeries, prolonged hospital stay, and antibiotic therapy involve high costs and loss of productivity. ${ }^{2}$

\section{Epidemiology}

Between $4 \%$ and $64 \%$ of open long-bone fractures and $1 \%-2 \%$ of prosthetic joints are complicated by infection. ${ }^{3,4}$ The rate of infection after revision joint-replacement surgery is much higher $(2 \%-20 \%) .{ }^{5}$ Even with advances in antimicrobial therapy and surgery for chronic osteomyelitis, a recurrence rate of $20 \%-30 \%$ is reported. ${ }^{6,7}$

\section{Pathophysiology}

Chronic osteomyelitis may result from inadequately treated hematogenous acute osteomyelitis or more commonly from a contiguous source of infection. The contiguous 
spread may follow treatment of open fracture, internal fixation of fractures, or prosthetic replacements.

Following infection of the bone, the inflammatory process causes obliteration and compression of the vascular channels. If the infection is not treated promptly, part of the bone undergoes necrosis, resulting in the formation of a sequestrum. Damage to the bone is also caused by cytokines like IL-1 and TNF, present at the site of infection. The surface of the sequestrum or implants provides a base for formation of the biofilm, made up of polysaccharide polymers that form a fibrous matrix around the host cells and bacteria. ${ }^{8}$ Inflammatory cells lead to further destruction of bone, and microorganisms propagate within the destroyed bone. With progress of the disease, new bone is formed around the sequestrum from the intact periosteum and endosteum, and is referred to as involucrum. The involucrum is perforated by openings known as cloacae.

A number of factors are responsible for chronicity of bone infection. The presence of sequestra, as well as foreign bodies like metal implants, contributes to the chronicity of infection, together with factors related to the pathogenic microorganism and the host.

Some bacteria have the ability to remain intracellular and hence not susceptible to routinely used antibiotics. Others produce a protective biofilm glycocalyx and also maintain a low metabolic rate. Host factors that impact on the outcome have been identified as obesity, smoking, and the presence of diabetes and peripheral vascular disease. ${ }^{9}$

The role of biofilm in orthopedic infections particularly related to the use of implants and prosthesis is now established, and has been the subject of numerous reviews. ${ }^{10-12}$ Briefly, biofilms develop on inert surfaces like implants or dead tissue like sequestra of bone. These develop in steps consisting of adhesion of microbe to the surface followed by multiplication. Later, an organized structure develops with high density of microorganisms surrounded by matrix. The last stage involves maturation of the biofilm. Some of the microorganisms are more virulent, causing further tissue destruction. In the depth of the biofilm, with limited access to oxygen and nutrients, microorganisms are inactive and form the persisters. Some biofilms also release planktonic microbes from the surface, which are capable of forming new biofilms. Microorganisms in the impervious biofilm are protected from the host's immune defenses like antibodies and phagocytosis, as well as administered antibiotics. Additional factors that decrease the susceptibility of bacteria in biofilms include a slow rate of growth, heterogeneity within the biofilm, quorum sensing, and induction of biofilm phenotype. ${ }^{10-12}$

\section{Microbiology}

Staphylococcus aureus is the most common microorganism isolated in up to two-thirds cases of chronic osteomyelitis in adults. This is followed by Enterococcus spp., Streptococcus spp., Pseudomonas aeruginosa, and Enterobacter spp. In some case Mycobacterium spp., anaerobes, and fungi have been reported. ${ }^{913-17}$ Multiple organisms are involved when osteomyelitis follows contiguous spread. As many as $30 \%$ of cases were noted to have polymicrobial infection in a large series. ${ }^{17}$ Recent challenges have been infection with methicillin-resistant $S$. aureus and multidrug-resistant organisms. Chronic osteomyelitis due to P. aeruginosa has a twofold-increased chance of recurrence compared to S. aureus. ${ }^{6}$

\section{Diagnosis \\ Clinical features}

There are no specific symptoms or signs of chronic osteomyelitis. The varied symptoms may include chronic pain, persistent discharge from a wound, presence of sinus tracts, and malaise. It may also present as a recurrent condition with periods of quiescence. ${ }^{1}$ During exacerbation of infection, the patient may report fever and increasing pain at the affected site.

Certain features like persistent sinus tracts (Figure 1), exposed bone, chronic wound over a fracture site or surgical
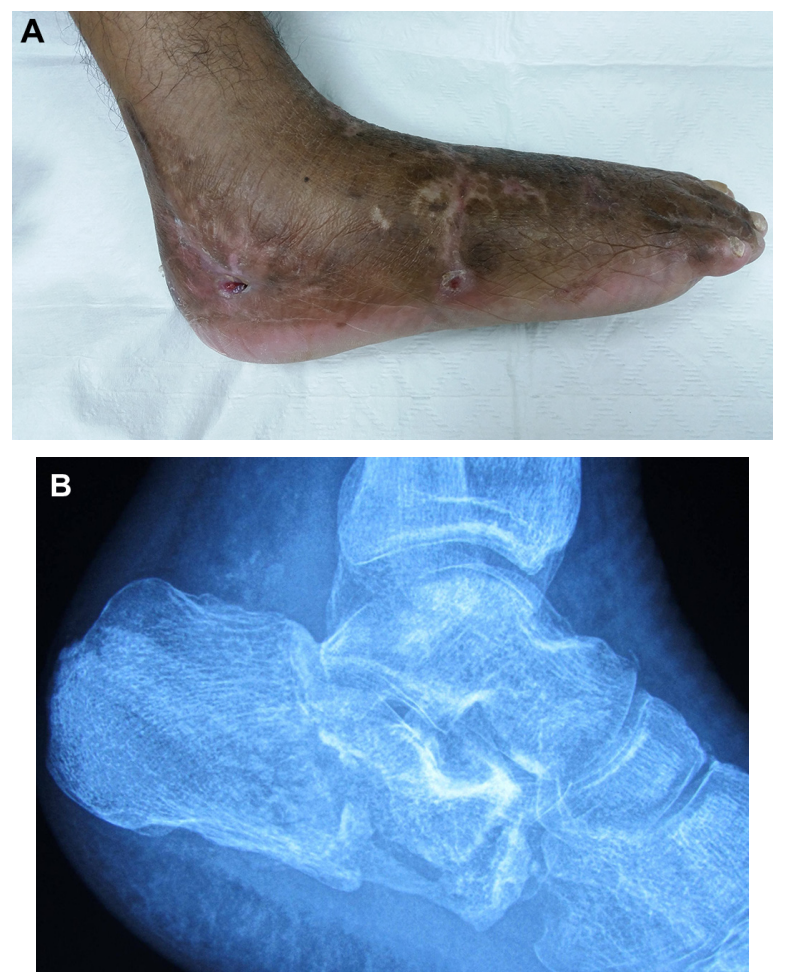

Figure I Typical discharging sinus over lateral aspect of heel (A) from underlying chronic osteomyelitis of the calcaneum (B) following an open fracture. 
implant (Figure 2), and tissue necrosis overlying bone should raise a suspicion of chronic osteomyelitis. This should be supported by laboratory and imaging studies, though a definitive diagnosis can only be made after bone biopsy and bacterial culture. ${ }^{18}$

\section{Classification}

Waldvogel et al classified osteomyelitis based on the presumed mechanism of infection into hematogenous or direct inoculation of bacteria into bone from contiguous soft-tissue infection or a chronic open wound. ${ }^{19}$ This classification is of limited use in clinical practice, as it does not help in any decision making for treatment and prognosis.

A widely used classification system for osteomyelitis was proposed by Cierny et al. ${ }^{20}$ This takes in to consideration the extent of bone involvement (Table 1), the physiologic class of the patient (Table 2), and systemic and local factors affecting immune-system response, metabolism, and local vascularity (Table 3 ). It has been shown to correlate with treatment and prognosis. ${ }^{21,22}$

Specific host factors, such as the presence of diabetes and chronic granulomatous diseases, etc may predispose an individual to develop osteomyelitis, while other factors are important for the containment of infection and its eradication once introduced. ${ }^{15}$

\section{Imaging}

Imaging studies are vital for the diagnosis and assessment of the extent of disease in chronic osteomyelitis. Accurate diagnosis will require a combination of various techniques. The treating clinician should be aware of the information each modality can provide, together with its limitations. ${ }^{23}$

Plain radiographs remain the first imaging modality, and can show the extent of bone involvement. Changes of periostitis/osteitis suggesting contamination of these tissues can be seen. Sequestrum, representing necrotic bone surrounded by infected granulation tissue and involucrum, the layer of new bone formed about the sequestrum, can also be noted on plain radiographs.

In chronic osteomyelitis, ultrasound imaging is helpful in localizing soft-tissue abscesses. In the presence of metal implants, ultrasound may offer useful information compared to computed tomography $(\mathrm{CT})$ or magnetic resonance imaging (MRI). CT offers multiplanar imaging, demonstrating clear changes in the bone seen in chronic osteomyelitis like extent of cortical involvement, encroachment of medullary canal, and chronic discharging sinus.
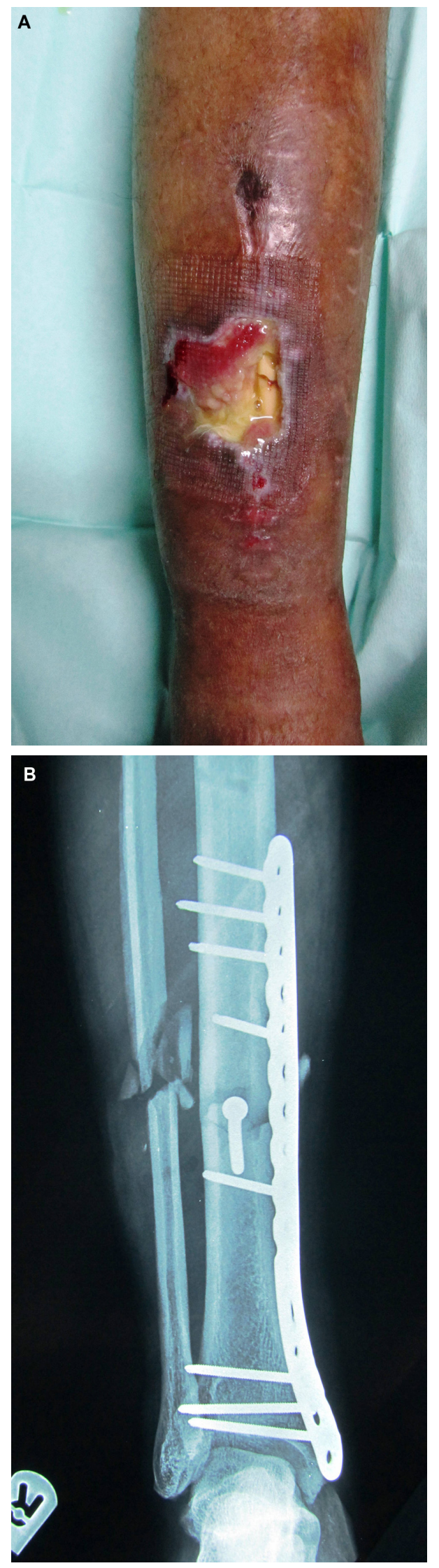

Figure 2 Exposed bone with breakdown of skin and soft tissue and discharge (A) following internal fixation of fracture of tibia (B). 
Table I Cierny-Mader staging for long-bone osteomyelitis ${ }^{20}$

\begin{tabular}{|c|c|c|c|c|}
\hline Stage & Anatomic type & Description & Causation & Recommended treatment \\
\hline I & Medullary & & $\begin{array}{l}\text { Infection following intramedullary } \\
\text { nailing }\end{array}$ & $\begin{array}{l}\text { Removal of infected implant } \\
\text { and intramedullary debridement }\end{array}$ \\
\hline 2 & Superficial & $\begin{array}{l}\text { Medullary canal and full thickness } \\
\text { of cortex not involved }\end{array}$ & $\begin{array}{l}\text { Chronic wound with colonization and } \\
\text { focal involvement of underlying bone }\end{array}$ & $\begin{array}{l}\text { Removal of affected bone till } \\
\text { viable vascular bone }\end{array}$ \\
\hline 3 & Localized & $\begin{array}{l}\text { Full-thickness cortical involvement, } \\
\text { medullary spread, stable uninvolved } \\
\text { segment of cortex at same level }\end{array}$ & $\begin{array}{l}\text { Following direct trauma with } \\
\text { devascularization and seeding } \\
\text { of bone }\end{array}$ & $\begin{array}{l}\text { Excision of infected tissue without } \\
\text { compromising stability of bone }\end{array}$ \\
\hline 4 & Diffuse & $\begin{array}{l}\text { Involvement of entire axial segment } \\
\text { leading to segmental defect on excision }\end{array}$ & $\begin{array}{l}\text { Major devascularization } \\
\text { with colonization }\end{array}$ & $\begin{array}{l}\text { Resection with reconstruction } \\
\text { of defect }\end{array}$ \\
\hline
\end{tabular}

It is particularly helpful in detecting sequestra that may be masked by surrounding osseous changes seen on plain radiographs. It can also help in guiding aspiration and biopsy to obtain samples for identification of the causative organism. MRI is helpful in the assessment of extent and activity of the disease, as well as vascularity and viability of the tissues (Figure 3). All of these factors are critical in making treatment decisions. The presence of metal implants may produce artifacts in MRI, which can affect the image quality.

Nuclear medicine imaging is more useful in cases with acute osteomyelitis compared to chronic osteomyelitis. Bone scintigraphy and leukocyte scintigraphy have been extensively used in the imaging of chronic osteomyelitis. Positron-emission tomography has higher accuracy in confirming or ruling out chronic osteomyelitis compared to bone scintigraphy or MRI. ${ }^{24}$

Sinography is a technique where contrast material is injected into the sinus opening to ascertain the course and extent of the sinus and its communication with deeper tissues. At surgery, complete excision of the sinus is an essential step. Additional information can be obtained when sinography is performed with CT.

In a systematic review and meta-analysis, Termaat et al found positron-emission tomography to be most sensitive (96\%) and specific (91\%) for the diagnosis of chronic osteomyelitis. The sensitivity and specificity of other modalities were $83 \%$ and $62 \%$ for MRI and $82 \%$ and $25 \%$ for scintigraphy, respectively. The sensitivity and specificity of combined bone and leukocyte scintigraphy was higher than that for individual modalities. ${ }^{25}$

\section{Laboratory workup and microbiology}

All patients with suspected osteomyelitis should have a complete blood count and markers of infection done. The white cell count may be normal in most cases. C-reactive protein and erythrocyte sedimentation rate are nonspecific, but are used to monitor response to treatment. In addition, renal function and blood glucose should be tested and nutritional status of the patient assessed using albumin and prealbumin. ${ }^{26}$

Samples must be obtained for Gram staining and culture and sensitivity to identify the causative organism. Samples from deeper tissue and bone biopsy are preferred over swabs. Multiple tissue samples should be collected from deep-wound surfaces like loculated collection, reactive granulations, and foreign bodies. ${ }^{27}$ The tissue samples should be subjected to anaerobic, aerobic, fungal, and mycobacterial culture in all cases.

Cultures obtained from sinus tracts are not reliable, and the absence of growth of microorganisms from tissue obtained by needle biopsy does not rule out chronic osteomyelitis. ${ }^{28}$ Low-virulence organisms may have to be subjected to prolonged incubation and culture. In certain cases, advanced techniques like polymerase chain-reaction DNA pyrosequencing may be used..$^{27,29}$

Table 2 Physiologic class of host

\begin{tabular}{|c|c|c|c|}
\hline Type & Status & Underlying factors & Treatment recommendation \\
\hline A & Normal physiologic response & Minimal or none, local or systemic factors & Surgery as appropriate \\
\hline B (local) & Local impairment & $\begin{array}{l}\text { Cellulitis, prior trauma, surgery, presence } \\
\text { of scar, or sinus }\end{array}$ & Address healing potential of local tissue \\
\hline B (systemic) & Systemic factors & $\begin{array}{l}\text { Coexistent diseases like diabetes, immunocompromise, } \\
\text { vascular disease, hypoproteinemia }\end{array}$ & $\begin{array}{l}\text { Treatment of correctable metabolic } \\
\text { and nutritional abnormality }\end{array}$ \\
\hline C & Severe infection & Severe systemic and local compromise & $\begin{array}{l}\text { Treatment worse than disease, } \\
\text { may need amputation }\end{array}$ \\
\hline
\end{tabular}


Table 3 Systemic and local factors affecting physiologic class of host

\begin{tabular}{ll}
\hline Systemic (Bs) & Local (BI) \\
\hline Malnutrition & Chronic lymphedema \\
Renal or hepatic failure & Major-vessel compromise \\
Diabetes mellitus & Small-vessel disease \\
Chronic hypoxia & Vasculitis \\
Malignancy & Venous stasis \\
Extremes of age & Extensive scarring \\
Immunosuppression or deficiency & Radiation fibrosis \\
& Neuropathy \\
& Tobacco abuse \\
\hline
\end{tabular}

\section{Treatment}

For evaluation of results of treatment of chronic osteomyelitis, a number of variables have to be taken into account. These would include the pathogenesis, stage of disease, causative microorganism, surgical procedure performed, and various host factors. There is a lack of comparative studies, and the published studies are heterogeneous. There is also a lack of uniformity in case selection and treatment given, as well as outcome measures used. ${ }^{14}$

With the diverse issues to be addressed in the management of chronic osteomyelitis, it is clear that a multidisciplinary effort is needed for successful treatment. The team should consist of surgeons (orthopedic and reconstructive surgery), an infectious disease specialist, a specialist to advise
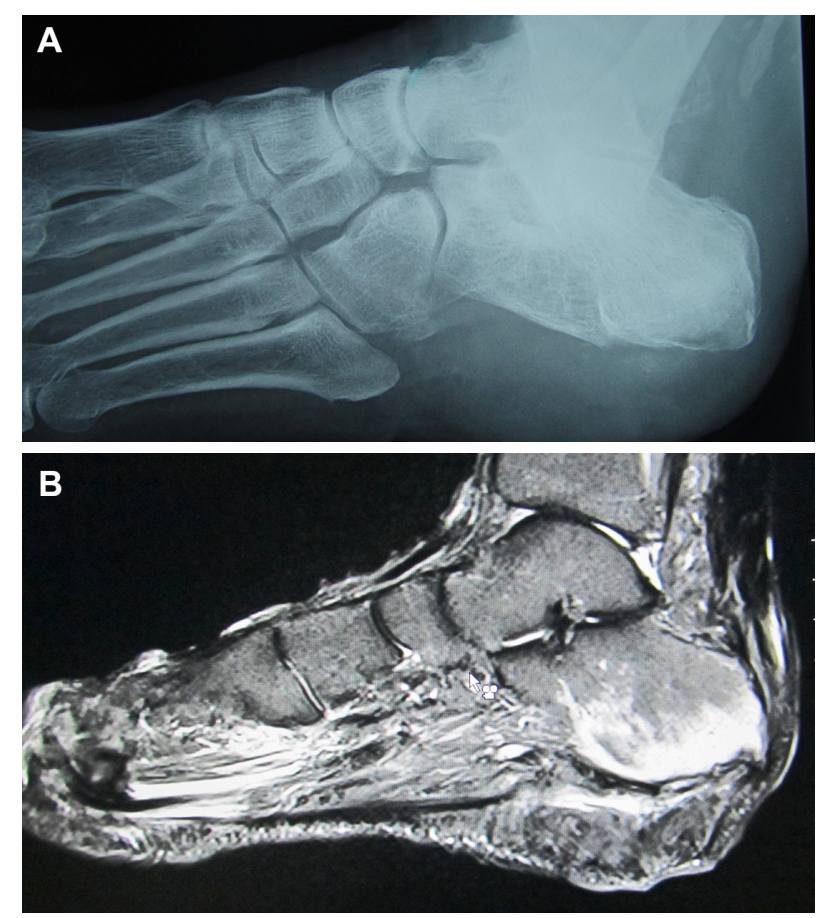

Figure 3 Chronic osteomyelitis of the calcaneum; normal plain radiograph (A), changes seen on MRI (B).

Abbreviation: MRI, magnetic resonance imaging. on nutrition, and a psychologist if needed. Salvana et al reported on their 7-year experience of treating 82 cases with a multidisciplinary bone-infection team. Infection was cured in 81 cases, and limb salvage was possible in 77 of 82 cases. ${ }^{30}$

The goal of treatment in chronic osteomyelitis is complete eradication of infection while preserving the soft-tissue envelope, healing of bone segment, and preservation of limb length and function. The treatment plan has to be individualized after assessing the extent of disease, microbiological study, and optimizing the patient's physiological status.

\section{Antibiotic therapy}

For the successful treatment of chronic osteomyelitis and eradication of infection, a properly designed antibiotictherapy regimen is vital. This should be based on the identification of the infective organism and its susceptibility. In this regard, knowledge of the spectrum of action of the antibiotic and its route of administration to achieve adequate levels in the bone is important.

The challenges for successful antibiotic therapy are the presence of devitalized, avascular tissue, biofilm formation, and the chemical environment at the site of infection. Some infective organisms in chronic osteomyelitis may be slow-replicating and thus less susceptible to certain groups of antibiotics.

The route of administration of the antibiotic is less important if the desired concentration can be achieved at the site of infection. Some of the antibiotics have good oral bioavailability, and can be given either orally or by an intravenous route (fluoroquinolones, linezolid); ${ }^{31}$ for others, parenteral therapy provides higher serum levels (cephalosporins), while some are only available for use in parenteral form (carbapenems, broad-spectrum cephalosporins, vancomycin, and aminoglycosides). ${ }^{32}$

Effective treatment of chronic osteomyelitis requires prolonged antimicrobial therapy. Oral therapy is simple, economical, more convenient for patients, and avoids risks associated with use of intravenous access. Patients requiring long-term intravenous access should be considered for peripherally inserted central catheters.

Mackintosh et al reported an overall success rate of $86 \%$ using outpatient parenteral antibiotic therapy (OPAT) for bone and joint infection. In subgroups, it was $72 \%$ for diabetic foot or stump infection compared to $100 \%$ for implantrelated infection. The factors associated with poor outcome were older age, methicillin-resistant $S$. aureus infection, and diabetic foot infection. ${ }^{33} \mathrm{~A}$ similar experience was reported with OPAT by Tice et al who found diabetes and peripheral 
vascular disease to be factors associated with recurrence. ${ }^{34}$ Lai et al successfully treated 333 patients with OPAT (393 courses), of which $40 \%$ had osteomyelitis. Hospital readmission for serious line-related complication was noted in only six $(1.5 \%)$ episodes. ${ }^{35}$

A review of studies on antibiotic therapy for osteomyelitis published between 1968 and 2000 concluded that there is inadequate evidence to recommend the best agent, route of administration, or duration of therapy. ${ }^{14}$ The most controversial issue concerning the treatment of chronic osteomyelitis is the duration of antibiotic therapy. The standard recommendation of use of antibiotics for 4-6 weeks is based on animal studies on time taken for revascularization of bone. Haider et al reviewed studies reporting use of shorter courses of antibiotics, and proposed their use particularly in cases where aggressive surgical debridement and procedures like a vascularized flap are performed to restore vascularity. ${ }^{36}$

Calhoun and Manring suggested the duration of antibiotic use be based on the Cierny-Mader stage of the disease. In stages I and II, a shorter course of antibiotics for 2 weeks may be adequate in conjunction with surgery. Stages III and IV may need antibiotics for 4-6 weeks, as even after adequate debridement the tissue bed may still be contaminated..$^{15}$

Spellberg and Lipsky reviewed publications from 1970 to 2011 related to the use of antibiotics in chronic osteomyelitis. The important conclusions from their review were 1) oral antibiotic therapy with agents that have high bioavailability is comparable with parenteral therapy, 2) improved cure rates with addition of rifampicin, 3) the duration of antibiotic therapy should be individualized based on clinical, hematological, and radiological response, and patients should be monitored after completion of therapy, and 4) the cure rate of chronic osteomyelitis is increased with surgical resection of infected and devitalized tissue in conjunction with antibiotic therapy. ${ }^{37}$

The use of various antimicrobial agents with their susceptibility profile and dosage regimen have been reviewed by a number of authors. . $^{14,32,37-40}$ The use of local antibiotic therapy has increased the options in successful management of chronic infection. The initial experience of local delivery of antibiotics was reported by Buchholz and Engelbrecht, with antibiotics mixed with cement providing higher antibiotic concentrations over a longer period of time in the setting of joint arthroplasty. ${ }^{41}$ It was later used for patients with open fractures and the treatment of chronic osteomyelitis. Klemm reported a cure rate of $91.4 \%$ using gentamicin-impregnated beads for dead-space management after debridement of infected bone. ${ }^{42}$
Local antibiotic therapy using antibiotic-impregnated cement beads helps in the management of dead space, delivering a high concentration of antibiotics locally, ${ }^{43}$ and it reduces the risk of parenteral antibiotic therapy together with its cost. While second surgery is needed for removal of the beads, the use of biodegradable agents obviates the need for this. Kluin et al reviewed the role of different biodegradable and nonbiodegradable antibiotic-delivery devices used in osteomyelitis. ${ }^{44}$

The most widely used substrate for delivery of local antibiotic has been polymethyl methacrylate cement (PMMA). The antibiotic to be used with PMMA has to be heat-stable and hydrophilic. The most commonly used antibiotics are gentamicin, tobramycin, and vancomycin. The broad spectrum of action, bactericidal properties, and heat stability make gentamicin an ideal additive with PMMA ${ }^{45}$ however, it is most effective against Gram-negative bacteria only.

In a study comparing debridement versus debridement and antibiotic-loaded bioabsorbable pellets, no difference in the healing rates was noted, except in a subgroup of patients with medullary osteomyelitis with a normal immune system. ${ }^{46}$ Recently, Ikpeme et al reported better results following surgical debridement with a local antibiotic-delivery system (PMMA beads and blocks and antibiotic irrigation and drainage group) compared with debridement and sequestrectomy. ${ }^{47}$

A useful option for chronic osteomyelitis with largebone defect is the Masquelet or the induced membrane technique. Placement of a PMMA spacer in the defect leads to the formation of a membrane that is very vascular and secretes growth factors. In the second stage, the removal of the PMMA spacer is followed by cancellous bone grafting or bone transport. ${ }^{48,49}$

Other substrates include protein-based materials, bonegraft substitutes, synthetic polymer, and metal. The last two are not yet commercially available or widely used..$^{50}$ Gitelis and Brebach reported successful outcomes with the use of biodegradable antibiotic-impregnated implant. ${ }^{51}$ In a prospective randomized trial, McKee et al compared antibiotic-impregnated cement beads versus bioabsorbable bone substitute in the treatment of chronic osteomyelitis and infected nonunion. The infection was eradicated in $86 \%$ of cases in both groups, but patients in the former group needed more reoperations. ${ }^{52}$

Recently, Ferguson et al reported resolution of infection in $98 \%$ of cases $(n=195)$ with a recurrence rate of $9.2 \%$ with the use of biodegradable calcium sulfate containing tobramycin. Prolonged ooze from the wound was noted in $15.4 \%$ of 
cases, but was seen to be self-limiting and not associated with recurrence. ${ }^{53}$

\section{Surgery}

The essential steps of surgical management of chronic osteomyelitis include adequate debridement, management of dead space, soft-tissue coverage, skeletal stabilization, and treatment of skeletal defects.

\section{Surgical debridement}

The cornerstone of successful treatment of chronic osteomyelitis is aggressive surgical debridement of infected and devitalized tissue, removal of foreign material, reconstruction of soft tissue and bone defects, and appropriate antimicrobial therapy. ${ }^{26}$ Most authors recommend wide excision with clear vascular margins and adequate soft-tissue cover for the treatment of chronic osteomyelitis, as inadequate debridement is associated with higher chances of recurrence. ${ }^{13,27,29,54,55}$ In a prospective study, $100 \%$ cure rates were noted after wide excision, while $100 \%$ recurrence rates were seen after local debulking. Furthermore, a 28\% recurrence rate was seen if the margin of resection was less than $5 \mathrm{~mm}$, particularly in type B hosts (Tables 2 and 3 ). ${ }^{56}$

There is slight variation in the approach to patients with infections associated with prosthetic implants and those associated with fracture fixation. Tafer et al presented an excellent review of the management of periprosthetic joint infection with approaches to deal with the implant. ${ }^{40}$ Healing of fracture is the primary aim with the use of internal fixation devices. Therefore, complete eradication of infection is not always necessary, and if the fixation is stable, the infected implant can be removed after healing of the fracture with treatment of residual infection (Figure 4). ${ }^{57}$ If there is failure of fixation in the presence of infection, implant removal should be done, followed by approaches discussed in this review.

\section{Dead-space management}

The dead space created after debridement should be managed properly while the infection is being treated. Various options available include mobilization of local muscle, rotational muscle flap, or a free-muscle flap.

The choice of flap or microvascular procedure depends on the size of defect. For smaller defects with soft-tissue loss, fasciocutaneous free flaps are recommended to reduce morbidity from the donor site. When faced with a large dead space, a free-muscle flap is preferable, while in cases with major bone loss, a free vascularized bone graft can be used, or composite grafts including bone, muscle, and/or skin can be used. ${ }^{58}$
Vacuum-assisted closure is useful in managing dead space in stages 2,3 , and 4 . In a study comparing its efficacy with conventional management of wounds, there was a significant reduction in recurrence of infection and need for plastic surgical procedure. ${ }^{59}$

A time-honored method for management of dead space is the use of antibiotic-impregnated PMMA. This can be used in the form of beads or blocks. The PMMA beads can be used both with an open or closed soft-tissue envelope. They can be retained longer if soft-tissue closure is possible. Their use necessitates second surgery for removal. The surgeon has an option of using commercially available beads or making their own beads by mixing PMMA with heatstable antibiotics mentioned earlier. The advantage of using antibiotic-impregnated PMMA blocks is that it augments local skeletal stability while maintaining length and space for later reconstructive procedures. Compared to the beads, there is less soft-tissue ingrowth. ${ }^{60}$

\section{Soft-tissue coverage}

To offer a well-vascularized soft-tissue envelope, microvascular free-muscle transfer is considered the gold standard. Other options include rotational muscle flaps. The timing of vascularized microsurgical procedure varies with the protocol planned. Doi et $\mathrm{al}^{61}$ and Rhomberg et al ${ }^{62}$ reported successful outcomes following a single-stage procedure, while Dinh et $\mathrm{al}^{63}$ advocated a two-stage procedure.

\section{Skeletal stabilization and management of skeletal defects}

Skeletal stabilization is needed for all stage 4 and some stage 3 lesions following excision of the devitalized bone. The preferred method of skeletal stabilization is external fixation. In some cases, it may be possible to convert this into internal fixation after control of infection. Paley and Herzenberg introduced the option of antibiotic bone cementimpregnated intramedullary nails to achieve stability and local delivery of antibiotics. ${ }^{64}$

Generally, defects less than $6 \mathrm{~cm}$ can be bridged by autogenous bone grafts such as a corticocancellous iliac crest. Larger defects are best bridged by distraction osteogenesis using an Ilizarov ring fixator or vascularized bone graft typically taken from the fibula.

For the management of bone defects, Ilizarov ring fixation with distraction osteogenesis has also been used, with Marsh et al reporting a 100\% cure rate at 1-year follow-up. This technique is time-consuming, and needs meticulous care during the course of treatment. ${ }^{65}$ 

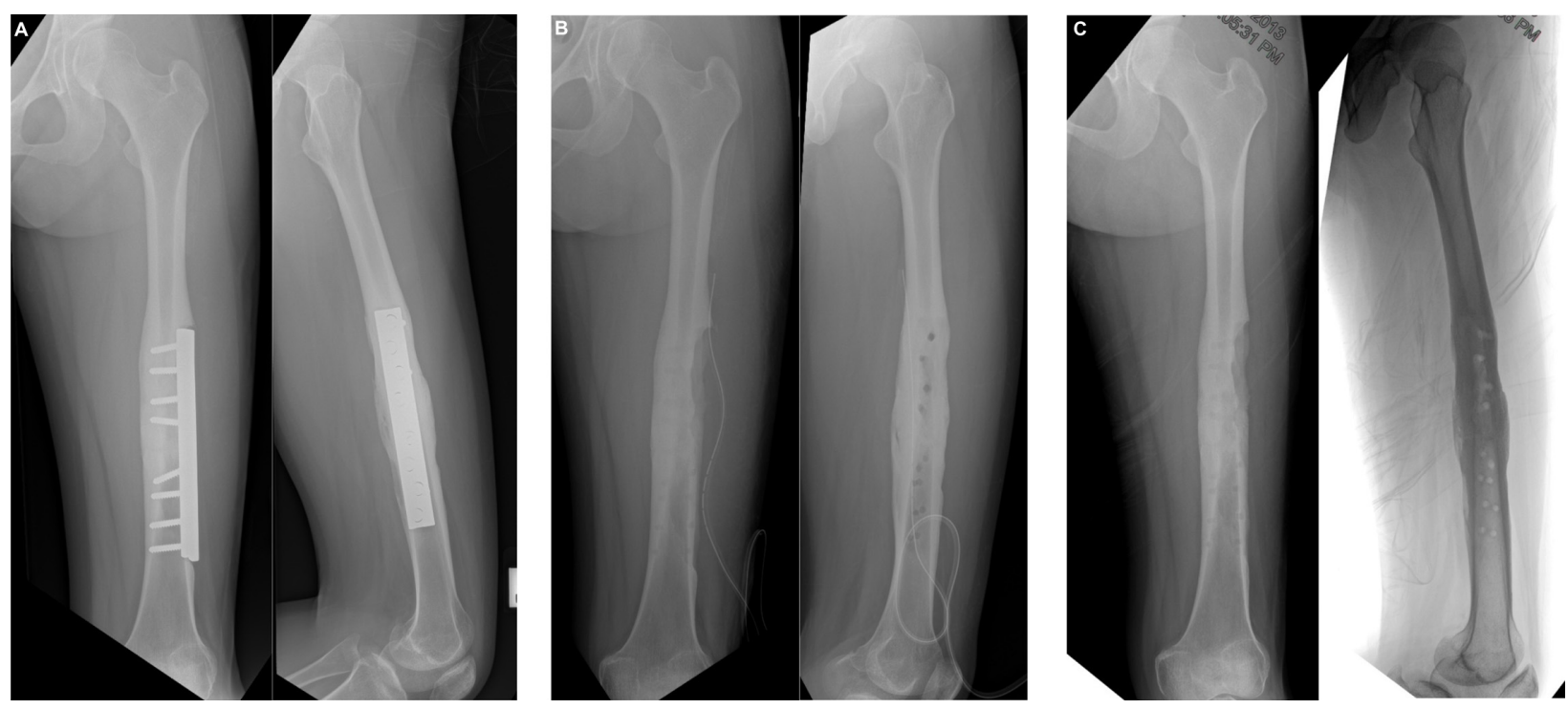

Figure 4 Chronic osteomyelitis associated with plating of femur, 2 year history of discharging sinus over lateral aspect of left thigh.

Notes: (A) Healed fracture of left femur with lucency around the plate. (B) Immediate postoperative radiograph showing extent of sequestrate excised from under the plate and bone debrided along with infected granulation tissue. (C) Six weeks after surgery and anti-microbial therapy.

The vascularized bone graft offers certain advantages, including providing autogenous corticocancellous grafts with intact blood supply. The process of their incorporation is different from avascular grafts, such that there is no necrosis or resorption. The mass, architecture, and biomechanical strength of the vascularized graft is maintained, and they also have ability to hypertrophy ${ }^{61}$ These can be obtained from the fibula, iliac crest, and ribs and transferred with skin, fascia, and muscle to fill soft-tissue defects. The success rate of vascularized fibular grafts has been reported to be between $77 \%$ and $90 \%{ }^{63,66-68}$ Complications with the use of vascularized bone grafts include failure of the anastomosis, fracture of the graft, and donor-site morbidity.

Typically, stage 1 infection is treated with intramedullary reaming and curettage. Primary closure is possible with limited dead space. In stage 2 , infections can be managed by soft-tissue debridement and curettage of the involved cortex. Larger defects may need soft-tissue coverage, done either as a single- or two-stage procedure. ${ }^{20}$

In stage 3 , the essential surgical steps include debridement of soft tissue and cortex, excision of the sequestrum, and decompression of the medullary canal. This process is also referred to as "saucerization". ${ }^{20}$ Additional procedures of soft-tissue defect and bone may be required based on the extent of involvement. Multiple staged procedures are most often needed for stage 4 infection to address osseous defect and stability. Various options are available for the management of segmental bone loss discussed earlier.
Certain named techniques have been proposed by their authors. In the Papineau technique, radical debridement is followed by bone grafting in stages and delayed soft-tissue closure, with the wound allowed to granulate naturally or with skin grafting. Stage 3 infections are best suited for this technique, as bone grafts do not provide the necessary stability. ${ }^{69}$

The Belfast technique, proposed by McNally et al, is a staged procedure involving radical debridement with early soft-tissue cover for elimination of dead space followed by delayed bone grafting. The authors reported a cure rate of $92 \%$ with this technique..$^{70}$

The Lautenbach technique, which was first described for infected total hip arthroplasty, has been used successfully for the management of chronic osteomyelitis. It is useful for cases with persistent infection after debridement and parenteral or oral antibiotic therapy. Using a closed irrigation system, antibiotics are delivered locally, and it is possible to obtain frequent samples for culture. Hashmi et al reported a series of 17 cases treated by this method with only one recurrence, which resolved after repeat treatment. ${ }^{71}$ Gokalp et al reported cures in 29 of 30 patients with chronic osteomyelitis treated by gutter creation in the affected bone with muscle-flap transposition. ${ }^{72}$

\section{Adjunctive therapies}

As discussed previously, chronic osteomyelitis is associated with impairment of local vascularity and destruction of bone. Various adjunctive therapies have been used in patients 
with a view to improving blood supply, tissue perfusion, and osteogenesis, the most tested of these being hyperbaric oxygen therapy.

Hyperbaric oxygen therapy can help in the management of chronic osteomyelitis by providing oxygen at high concentration and pressure in diseased tissues that are known to be hypoxic. It also improves the bactericidal ability of the neutrophils, and helps neutralize collagen synthesis and osteogenesis. Other proposed mechanisms for its efficacy are inducing angiogenesis, suppressing anaerobic organisms, enhancing antibiotic activity, and promoting oxygendependent osteoclastic resorption of necrotic bone. ${ }^{73,74}$

Chen et $\mathrm{al}^{75}$ and Chen et $\mathrm{al}^{76}$ have reported on successful treatment of chronic osteomyelitis using hyperbaric oxygen therapy. Skeik et al retrospectively reviewed 118 patients where hyperbaric oxygen was used for different indications. In $82.6 \%$ of 23 cases of chronic refractory osteomyelitis, successful outcomes were noted. ${ }^{77}$

There is a lack of guidelines for use as well as high-quality clinical trials for hyperbaric oxygen in chronic osteomyelitis. The available literature however suggests great potential for this modality. Its use is limited by the cost, availability, and the risks involved, however. ${ }^{73,78}$

In animal models, gene therapy and use of growth factors like bone morphogenic protein has been shown to accelerate osteogenesis and bone healing. Similarly, pulsed electromagnetic fields, ultrasound, and platelet-rich plasma have been used to promote bone and soft-tissue healing. ${ }^{78}$

The most promising development in this field is the understanding of the genetic and molecular biology of bacterial biofilm. The formation of biofilm is an important pathogenic factor for bacterial resistance and persistence of infection in chronic osteomyelitis. Based on the understanding of cell-tocell signaling between bacteria, which helps them to organize into a biofilm, efforts are being made to prevent biofilm formation by inhibiting signals. ${ }^{79}$ The alternative strategies resulting from our understanding of the role of biofilm in chronic infection include quorum-sensing inhibitors (mentioned earlier), bacteriophages, interspecies interaction, biofilm disruptors (sonication), and specific antibiofilm molecules. ${ }^{10,12}$

In relation to orthopedic implants, suggested strategies for biofilm infections include the use of microporous calcium phosphate for local delivery of antimicrobial peptides, ${ }^{80}$ embedding of antimicrobial substances in nanoceramics, ${ }^{81}$ and surface modification of implants to reduce $S$. aureus attachment and biofilm formation. ${ }^{82}$ Harro et al presented a review of the history and development of bacterial vaccines with the challenges in developing a vaccine for clinical use. ${ }^{83}$ In a rat model of osteomyelitis, vaccination against $S$. aureus has been noted to induce reductions in bacterial load and bone morphological changes. ${ }^{84}$

Bioactive glass works by interfering with production of biofilm. Drago et al have confirmed the efficacy of bioactive glass both in vitro and in vivo for the treatment of chronic osteomyelitis, particularly with multiresistant strains and immunocompromised hosts. ${ }^{85}$ In another comparative study by the same group, similar eradication of infection was noted with the use of bioactive glass without antibiotics compared with two different antibiotic-loaded bone substitutes. ${ }^{86}$

\section{Conclusion}

Management of chronic osteomyelitis is challenging and prolonged, due to the nature of surgical procedures and antimicrobial therapy needed. While a number of options for surgical reconstruction and delivery of appropriate antibiotics are available, proper staging and identification of causative organism remains vital to the success of treatment. Newer treatment modalities are being developed to address the role of biofilm in chronic osteomyelitis.

\section{Disclosure}

The author reports no conflicts of interest in this work.

\section{References}

1. Mouzopoulos G, Kanakaris NK, Kontakis G, Obakponovwe O, Townsend R, Giannoudis PV. Management of bone infections in adults: the surgeon's and microbiologist's perspectives. Injury. 2011;42 Suppl 5: S18-S23.

2. Masini BD, Waterman SM, Wenke JC, Owens BD, Hsu JR, Ficke JR. Resource utilization and disability outcome assessment of combat casualties from Operation Iraqi Freedom and Operation Enduring Freedom. J Orthop Trauma. 2009;23:261-266.

3. Kurtz SM, Lau E, Schmier J, Ong KL, Zhao K, Parvizi J. Infection burden for hip and knee arthroplasty in the United States. J Arthroplasty. 2008;23:984-991.

4. Schenker ML, Yannascoli S, Baldwin KD, Ahn J, Mehta S. Does timing of operative debridement affect infectious complications in open long fractures? A systematic review. J Bone Joint Surg Am. 2012;94: 1057-1064.

5. Lentino JR. Prosthetic joint infections: bane of orthopedists, challenge for infectious disease specialists. Clin Infect Dis. 2003;36: 1157-1161.

6. Tice AD, Hoaglund PA, Shoultz DA. Risk factors and treatment outcomes in osteomyelitis. J Antimicrob Chemother. 2003;51:1261-1268.

7. Conterno LO, Turchi MD. Antibiotics for treating chronic osteomyelitis in adults. Cochrane Database Syst Rev. 2013;9:CD004439.

8. Gristina AG, Oga M, Webb LX, Hobgood CD. Adherent bacterial colonization in the pathogenesis of osteomyelitis. Science. 1985;228: 990-993.

9. Ciampolini J, Harding KG. Pathophysiology of chronic bacterial osteomyelitis. Why do antibiotics fail so often? Postgrad Med J. 2000;76: 479-483. 
10. Aparna MS, Yadav S. Biofilms: microbes and disease. Braz J Infect Dis. 2008;12:526-530.

11. Zimmerli W, Moser C. Pathogenesis and treatment concepts of orthopaedic biofilm infections. FEMS Immunol Med Microbiol. 2012;65: $158-168$.

12. Cedric J, Jocelyne C. Impact of bacterial biofilm on the treatment of prosthetic joint infections. J Antimicrob Chemother. 2014;69 Suppl 1: i37-i40.

13. Lew DP, Waldvogel FA. Osteomyelitis. Lancet. 2004;364:369-379.

14. Lazzarini L, Lipsky BA, Mader JT. Antibiotic treatment of osteomyelitis: what have we learned from 30 years of clinical trials? Int J Infect Dis. 2005;9:127-138.

15. Calhoun JH, Manring MM. Adult osteomyelitis. Infect Dis Clin North Am. 2005;19:765-786.

16. Jorge LS, Chueire AG, Baptista AR: Osteomyelitis: a current challenge. Braz J Infect Dis. 2010;14:310-315.

17. Sheehy SH, Atkins BA, Bejon P, et al. The microbiology of chronic osteomyelitis: prevalence of resistance to common empirical antimicrobial regimens. J Infect. 2010;60:338-343.

18. American Society of Plastic Surgeons. Evidence based clinical practice guideline: chronic wounds of the lower extremity. 2007. Available from: http://www.plasticsurgery.org/Documents/medical-professionals/ health-policy/evidence-practice/Evidence-based-Clinical-PracticeGuideline-Chronic-Wounds-of-the-Lower-Extremity.pdf. Accessed April 22, 2015.

19. Waldvogel FA, Medoff G, Swartz MN. Osteomyelitis: a review of clinical features, therapeutic considerations and unusual aspects. $N E n g l$ J Med. 1970;282:198-206.

20. Cierny G 3rd, Mader JT, Pennick JJ. A clinical staging system for adult osteomyelitis. Clin Orthop Relat Res. 2003;414:7-24.

21. Cierny G 3rd. Chronic osteomyelitis: results of treatment. Instr Course Lect. 1990;39:495-508.

22. Bowen TR, Widmaier JC. Host classification predicts infection after open fracture. Clin Orthop Relat Res. 2005;433:205-211.

23. Pineda C, Espinosa R, Pena A. Radiographic imaging in osteomyelitis: the role of plain radiography, computed tomography, ultrasonography, magnetic resonance imaging and scintigraphy. Semin Plast Surg. 2009;23:80-89.

24. Santiago Restrepo C, Giménez CR, McCarthy K. Imaging of osteomyelitis and musculoskeletal soft tissue infections: current concepts. Rheum Dis Clin North Am. 2003;29:89-109.

25. Termaat MF, Raijmakers PG, Scholtein HJ, Bakker FC, Patka P, Haarman HJ. The accuracy of diagnostic imaging for the assessment of chronic osteomyelitis: a systematic review and meta-analysis. J Bone Joint Surg Am. 2005;87:2464-2471.

26. Lazzarini L, Mader JT, Calhoun JH. Osteomyelitis in long bones. J Bone Joint Surg Am. 2004;86-A:2305-2318.

27. Forsberg JA, Potter BK, Cierny G 3rd, Webb L. Diagnosis and management of chronic infection. J Am Acad Orthop Surg. 2011;19 Suppl 1: S8-S19.

28. Perry CR, Pearson RL, Miller GA. Accuracy of cultures of material from swabbing of the superficial aspect of the wound and needle biopsy in the preoperative assessment of osteomyelitis. J Bone Joint Surg Am. 1991;73:745-749.

29. Cierny G 3rd. Surgical treatment of osteomyelitis. Plast Reconstr Surg. 2011;127 Suppl 1:190S-204S.

30. Salvana J, Rodner C, Browner BD, Livingston K, Schreiber J, Pesanti E. Chronic osteomyelitis: results obtained by an integrated team approach to management. Conn Med. 2005;69:195-202.

31. Mader JT, Cantrell JS, Calhoun J. Oral ciprofloxacin therapy compared with standard parenteral antibiotic therapy for chronic osteomyelitis in adults. J Bone Joint Surg Am. 1990;72:104-110.

32. Fraimow HS. Systemic antimicrobial therapy in osteomyelitis. Semin Plast Surg. 2009;23:90-99.

33. Mackintosh CL, White HA, Seaton RA. Outpatient parenteral antibiotic therapy (OPAT) for bone and joint infections: experience from a UK teaching hospital-based service. J Antimicrob Chemother. 2011;66:408-415.
34. Tice AD, Hoaglund PA, Shoultz DA. Outcomes of osteomyelitis among patients treated with outpatient parenteral antimicrobial therapy. Am J Med. 2003;114:723-728.

35. Lai A, Tran T, Nguyen HM, Fleischmann J, Beenhouwer DO, Graber CJ. Outpatient parenteral antimicrobial therapy at large veterans administration medical center. Am J Manag Care. 2013;19:e317-e324.

36. Haidar R, Boghossain AD, Atiyeh B. Duration of post-surgical antibiotics in chronic osteomyelitis: empiric or evidence-based? Int J Infect Dis. 2010;14:e752-e758.

37. Spellberg B, Lipsky BA. Systemic antibiotic therapy for chronic osteomyelitis in adults. Clin Infect Dis. 2012;54:393-407.

38. Hatzenbuehler J, Pulling TJ. Diagnosis and management of osteomyelitis. Am Fam Physician. 2011;84:1027-1033.

39. Sendi P, Zimmerli W. Antimicrobial treatment concepts for orthopaedic device-related infection. Clin Microbiol Infect. 2012;18: 1176-1184.

40. Tafer N, Belaieff W, Cuerel C, Zingg M, Hoffmeyer P, Uckay I. Optimal diagnosis, prevention, and management of periprosthetic joint infection. Orthop Res Rev. 2015;7:11-19.

41. Buchholz HW, Engelbrecht H. [Depot effects of various antibiotics mixed with Palacos resins]. Chirurg. 1970;41:511-515. German.

42. Klemm K. [Gentamicin-PMMA-beads in treating bone and soft tissue infections (author's trans1)]. Zentralbl Chir. 1979;104:934-942. German.

43. Hoff SF, Fitzgerald RH Jr, Kelly PJ. The depot administration of penicillin $\mathrm{G}$ and gentamicin in acrylic bone cement. J Bone Joint Surg Am. 1981;63:798-804.

44. Kluin OS, van der Mei HC, Busscher HJ, Neut D. Biodegradable vs non-biodegradable antibiotic delivery devices in the treatment of osteomyelitis. Expert Opin Drug Deliv. 2013;10:341-351.

45. Klemm K. The use of antibiotic-containing bead chains in the treatment of chronic bone infections. Clin Microbiol Infect. 2001;7:28-31.

46. Chang W, Colangeli M, Colangeli S, Di Bella C, Gozzi E, Donati D. Adult osteomyelitis: debridement versus debridement plus Osteoset T pellets. Acta Orthop Belg. 2007;73:238-243.

47. Ikpeme IA, Oku EO, Ngim NE, Ilori IU, Abang IE. Comparison of the outcome of treatment of chronic osteomyelitis by surgical debridement with and without local antibiotic delivery system: experience from a Nigerian Teaching Hospital. Int J Clin Med. 2013;4:313-318.

48. Masquelet AC, Begue T. The concept of induced membrane for reconstruction of long bone defects. Orthop Clin N Am. 2010;41:27-37.

49. Marais LC, Ferreira N. Bone transport through an induced membrane in the management of tibial bone defects resulting from chronic osteomyelitis. Strategies Trauma Limb Reconstr. 2015;10:27-33.

50. McLaren AC. Alternative materials to acrylic bone cement for delivery of depot antibiotics in orthopaedic infections. Clin Orthop Relat Res. 2004;427:101-106.

51. Gitelis S, Brebach GT. The treatment of chronic osteomyelitis with a biodegradable antibiotic-impregnated implant. J Orthop Surg (Hong Kong). 2002;10:53-60.

52. McKee MD, Li-Band EA, Wild LM, Schemitsch EH. A prospective randomized clinical trial comparing on antibiotic-impregnated bioabsorbable bone substitute with standard antibiotic-impregnated cement beads in the treatment of chronic osteomyelitis and infected nonunion. J Orthop Trauma. 2010;24:483-490.

53. Ferguson JY, Dudareva M, Riley ND, Stubbs D, Atkins BL, McNally MA. The use of a biodegradable antibiotic-loaded calcium sulphate carrier containing tobramycin for the treatment of chronic osteomyelitis: a series of 195 cases. Bone Joint J. 2014;96-B: 829-836.

54. Tetsworth K, Cierny G 3rd. Osteomyelitis debridement techniques. Clin Orthop Relat Res. 1999;360:87-96.

55. Sanders J, Mauffrey C. Long bone osteomyelitis in adults: fundamental concepts and current techniques. Orthopedics. 2013;36:368-375.

56. Simpson AH, Deakin M, Lathan JM. Chronic osteomyelitis. The effect of the extent of surgical resection on infection-free survival. J Bone Joint Surg Br. 2001;83:403-407. 
57. Trampuz A, Widmer AF. Infections associated with orthopedic implants. Curr Opin Infect Dis. 2006;19:349-356.

58. Verhelle N, Van Zele D, Liboutton L, Heymans O. How to deal with bone exposure and osteomyelitis: an overview. Acta Orthop Belg. 2003;69:481-494.

59. Tan Y, Wang X, Li H, et al. The clinical efficacy of the vacuum-assisted closure therapy in the management of adult osteomyelitis. Arch Orthop Trauma Surg. 2011;131:255-259.

60. Gogia JS, Meehan JP, Di Cesare PE, Jamali AA. Local antibiotic therapy in osteomyelitis. Semin Plast Surg. 2009;23:100-107.

61. Doi K, Kawakami F, Hiura Y, Oda T, Sakai K, Kawai S. One-stage treatment of infected bone defects of the tibia with skin loss by free vascularized osteocutaneous grafts. Microsurgery. 1995;16:704-712.

62. Rhomberg M, Frischhut B, Ninkovic M, Schwabegger AH. A singlestage operation in the treatment of chronic osteomyelitis of the lower extremity including reconstruction with free vascularized iliac bone graft and free-tissue transfer. Plast Reconstr Surg. 2003;111:2353-2361.

63. Dinh P, Hutchinson BK, Zalavaras C, Stevanovic MV. Reconstruction of osteomyelitis defects. Semin Plast Surg. 2009;23:108-118.

64. Paley D, Herzenberg JE. Intramedullary infections treated with antibiotic cement rods: preliminary results in nine cases. J Orthop Trauma. 2002;16:723-729.

65. Marsh DR, Shah S, Elliott J, Kurdy N. The Ilizarov method in nonunion, malunion and infection of fractures. J Bone Joint Surg Br. 1997;79: 273-279.

66. Han CS, Wood MB, Bishop AT, Cooney WP 3rd. Vascularized bone transfer. J Bone Joint Surg Am. 1992;74:1441-9.

67. Yajima H, Kobata Shigemetsu K, et al. Vascularized fibular grafting in the treatment of methicillin-resistant Staphylococcus aureus osteomyelitis and infected nonunion. J Reconstr Microsurg. 2004;20:13-20.

68. Lê Thua TH, Pham DN, Boeckx W, De Mey A. Vascularized fibular transfer in longstanding and infected large bone defects. Acta Orthop Belg. 2014;80:50-55.

69. Papineau LJ, Allfageme A, Dalcourt JP, Pilon L. [Chronic osteomyelitis: open excision and grafting after saucerization (author's transl)]. Int Orthop. 1979;3:165-176. French.

70. McNally MA, Small JO, Tofighi HG, Mollan RA. Two-stage management of chronic osteomyelitis of the long bones. The Belfast technique. J Bone Joint Surg Br. 1993;75:375-380.

71. Hashmi MA, Norman P, Saleh M. The management of chronic osteomyelitis using the Lautenbach method. J Bone Joint Surg Br. 2004;86: 269-275.

72. Gokalp MA, Guner S, Ceylan MF, Doğan A, Sebik A. Results of treatment of chronic osteomyelitis by "gutter procedure and muscle flap transposition operation”. Eur J Orthop Surg Traumatol. 2014;24: 415-419.
73. Gill AL, Bell CN. Hyperbaric oxygen: its uses, mechanisms of action and outcomes. QJM. 2004;97:385-395.

74. Kawashima M, Tamura H, Nagayoshi I, Takao K, Yoshida K, Yamaguchi T. Hyperbaric oxygen therapy in orthopedic conditions. Undersea Hyperb Med. 2004;31:155-162.

75. Chen CY, Lin KP, Lu SH, Chen YJ, Lin CF. Adjuvant hyperbaric oxygen therapy in the treatment of hemodialysis patients with chronic osteomyelitis. Ren Fail. 2008;30:233-237.

76. Chen CE, Shih ST, Fu TH, Wang JW, Wang CJ. Hyperbaric oxygen therapy in the treatment of chronic refractory osteomyelitis: a preliminary report. Chang Gung Med J. 2003;26:114-121.

77. Skeik N, Porten BR, Isaacson E, et al. Hyperbaric oxygen treatment outcome for different indications from a single center. Ann Vasc Surg. 2015;29:206-214

78. Fang RC, Galiano RD. Adjunctive therapies in the treatment of osteomyelitis. Semin Plast Surg. 2009;23:141-147.

79. Costerton JW. Biofilm theory can guide the treatment of device-related orthopaedic infections. Clin Orthop Relat Res. 2005;437:7-11.

80. Kazemzadeh-Narbat M, Kindrachuk J, Duan K, Jenssen H, Hancock RE, Wang R. Antimicrobial peptides on calcium phosphate-coated titanium for the prevention of implant-associated infections. Biomaterials. 2010;31:9519-9526.

81. Simchi A, Tamjid E, Pishbin F, Boccaccini AR. Recent progress in inorganic and composite coatings with bactericidal capability for orthopaedic applications. Nanomedicine. 2011;7:22-39.

82. Khoo X, O'Toole GA, Nair SA, Snyder BD, Kenan DJ, Grinstaff MW. Staphylococcus aureus resistance on titanium coated with multivalent PEGylated-peptides. Biomaterials. 2010;31:9285-9292.

83. Harro JM, Peters BM, O’May GA, et al. Vaccine development on Staphylococcus aureus: taking the biofilm phenotype into consideration. FEMS Immunol Med Microbiol. 2010;59:306-323.

84. Lattar SM, Noto Llana M, Denoël P, et al. Protein antigens increase the protective efficacy of a capsule-based vaccine against Staphylococcus aureus in a rat model of osteomyelitis. Infect Immun. 2014;82:83-91.

85. Drago L, Romanò D, De Vecchi E, et al. Bioactive glass BAG-S53P4 for the adjunctive treatment of chronic osteomyelitis of the long bones: an in vitro and prospective clinical study. BMC Infect Dis. 2013;13:584.

86. Romanò CL, Logoluso N, Meani E, et al. A comparative study of the use of bioactive glass S53P4 and antibiotic-loaded calcium-based bone substitutes in the treatment of chronic osteomyelitis: a retrospective comparative study. Bone Joint J. 2014;96-B:845-850.
Orthopedic Research and Reviews

\section{Publish your work in this journal}

Orthopedic Research and Reviews is an international, peer-reviewed, open access journal focusing on the patho-physiology of the musculoskeletal system, trauma, surgery and other corrective interventions to restore mobility and function. Advances in new technologies, materials, techniques and pharmacological agents are particularly welcome. The journal welcomes

\section{Dovepress}

original research, clinical studies, reviews \& evaluations, expert opinion and commentary, case reports and extended reports. The manuscript management system is completely online and includes a very quick and fair peer-review system, which is all easy to use. Visit http://www.dovepress. com/testimonials.php to read real quotes from published authors. 